\title{
Obstructive urolithiasis in buffalo calves (Bubalus bubalis): Serum changes of Vitamins $A$ and $D$ and efficacy of surgical management using tube cystostomy
}

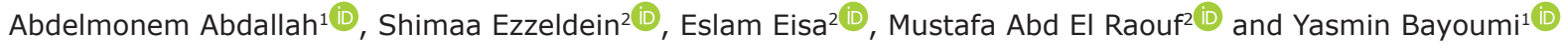 \\ 1. Department of Animal Medicine, Faculty of Veterinary Medicine, Zagazig University, 44519, Zagazig, Sharkia, Egypt; \\ 2. Department of Surgery, Anesthesiology and Radiology, Faculty of Veterinary Medicine, Zagazig University, 44519, \\ Zagazig, Sharkia, Egypt. \\ Corresponding author: Abdelmonem Abdallah, e-mail: abd.el.monem.ali@umontreal.ca \\ Co-authors: SE: shimaa.ezzeldein@yahoo.com, EE: efessa785@gmail.com, MA: dr_mustafa13@yahoo.com, \\ YB: yasmin.dream@yahoo.com \\ Received: 30-08-2020, Accepted: 01-12-2020, Published online: 18-01-2021
}

doi: www.doi.org/10.14202/vetworld.2021.129-136 How to cite this article: Abdallah A, Ezzeldein S, Eisa E, Abd El Raouf M, Bayoumi Y (2021) Obstructive urolithiasis in buffalo calves (Bubalus bubalis): Serum changes of Vitamins A and D and efficacy of surgical management using tube cystostomy, Veterinary World, 14(1): 129-136.

\begin{abstract}
Background and Aim: Obstructive urolithiasis is one of the major health problems in livestock animals, mainly in young calves. The present study was designed first to investigate the changes in the serum levels of Vitamins A and D in buffalo calves (Bubalus bubalis) with obstructive urolithiasis and second to investigate the efficacy of tube cystostomy technique in management of such condition.
\end{abstract}

Materials and Methods: One hundred and forty-nine buffalo calves of variable ages ranged from 3 to 7 months with a history of retained urine were examined clinically and ultrasonographically. Then, they were subjected to surgical treatment using the tube cystostomy technique. The serum levels of Vitamins A and D were investigated in retained urine calves in addition to 10 clinically healthy calves of the same age used as a control group.

Results: Based on clinical and ultrasonographic findings, the calves were diagnosed as obstructive urolithiasis with intact bladder ( $n=64$ calves) or with bladder rupture $(n=85$ calves) with the peak incidence in winter months. Tube cystostomy was an efficient and quick surgical technique for the management of such condition and $95.3 \%$ of calves returned their normal urination within 7-14 days after surgery. Significant hypovitaminoses A and D were found between retained urine calves and control ones $(\mathrm{p}=0.01$ and 0.002 , respectively).

Conclusion: Hypovitaminoses A and D suggested predisposing obstructive urolithiasis in buffalo calves, but further clinical studies are recommended for more confirmation. Surgical treatment using tube cystostomy technique is recommended for the management of obstructive urolithiasis in buffalo calves.

Keywords: buffalo calves, hypovitaminosis, tube cystostomy, ultrasound, urolithiasis.

\section{Introduction}

Obstructive urolithiasis is a worldwide disease of major importance in domestic animals. It was found to be the $5^{\text {th }}$ most prevalent cause of death in feedlots [1]. It is described as the concretion of urinary calculi which may lodge anywhere in the urinary system but usually at the distal end of the sigmoid flexure in ruminants [2,3]. Urolithiasis is considered a major problem mainly in males due to the anatomical conformation of their urinary tract [4]. The disease is highly incident in the male buffalo calves than the cow calves. Furthermore, it is more frequently occurred in the winter season rather than other seasons [5-7]. Surgical management is efficient in curing most cases [8]. Surgical interference includes perineal

Copyright: Abdallah, et al. Open Access. This article is distributed under the terms of the Creative Commons Attribution 4.0 International License (http://creativecommons.org/licenses/ by/4.0/), which permits unrestricted use, distribution, and reproduction in any medium, provided you give appropriate credit to the original author(s) and the source, provide a link to the Creative Commons license, and indicate if changes were made. The Creative Commons Public Domain Dedication waiver (http:// creativecommons.org/publicdomain/zero/1.0/) applies to the data made available in this article, unless otherwise stated. urethrostomy [9], tube cystostomy [4,10-13], urinary bladder marsupialization [14], and penile catheterization and amputation [15].

Urinary calculi formation is a multifactorial process that results from a combination of physiologic, nutritional, and management factors as the diet, age, sex, breed, genetic makeup, season, soil, water, hormone levels, mineral, infection, and other factors usually incorporated in the genesis of urolithiasis [2]. Additional factors have been incriminated as contributing causes, from those factors, the heavy concentrate-low roughage diets, limited intake of water, dehydration, urine alkalinity, mineralized artesian water, alkaline water supplies, excess of sodium bicarbonate in diet, Vitamin A deficiency, and hypervitaminosis D $[4,16]$. Experimental Vitamin A-free diet was reported to be a risk factor for urinary calculi formation in treated male rats versus a control group [17]. Hypervitaminosis D was previously reported to be a predisposing or risk factor for urinary calculi formation in swine and ruminants $[18,19]$. In human medicine, the literatures were controversial. A meta-analysis study reported that 25-hydroxyvitamin 
D serum levels are higher in kidney stone patients [20]. On the other hand, some studies showed a considerable prevalence of Vitamin D deficiency in stone formers compared with non-stone formers [21-24]. Despite the great economic importance of obstructive urolithiasis consequences that could be fatal in some cases, the disease is present and several cases or even outbreaks reported yearly.

The present study aimed first to investigate the changes in the serum levels of Vitamin A and D in buffalo calves (Bubalus bubalis) with obstructive urolithiasis and second to investigate the efficacy of tube cystostomy technique in management of such condition.

\section{Materials and Methods}

\section{Ethical approval}

The study protocol was designed according to the Ethics Committee of the Egyptian Veterinary Medicine Authority.

\section{Study location, period and Animals}

A total of 149 non-castrated male buffalo calves aging 3-7 months were admitted to the clinic of the Faculty of Veterinary Medicine, Zagazig University, with a history of retained urine during the period between June 2018 and June 2020. Ten apparently healthy non-castrated male buffalo calves of the same age were used as a control group for biochemical analysis.

\section{Clinical examination}

All calves were undergone a thorough clinical examination as described previously [25]. Data concerning age, days of retention, and food and water intake were recorded. Rectal body temperature, respiration rate, and heart rate were investigated using standard techniques. The color of the eye mucus membrane and the dehydration degree through skin tent test were examined. Abdominal distension and ballottement for fluid thrilling were reported. Abdominocentesis at the left paramedian site behind umbilicus was performed using a sterile 18-gauge needle under aseptic precautions in standing animals. Preoperatively, severely dehydrated animals were stabilized with fluid therapy as required and then operated with tube cystostomy on the same day.

\section{Biochemical analysis}

Before surgical interference, blood samples were drained from the jugular vein of the affected calves in plain sterile tubes without anticoagulant, then centrifuged and sera were harvested. Spectrophotometrically, serum calcium, inorganic phosphorus, creatinine, and blood urea nitrogen levels were determined by standard procedures using (Diagnostic Zrt. Commercial kits, Biomerieux). Serum levels of Vitamins A and D were measured using ELISA kits (Cat No. MBS267174 and CSB-E0809r, respectively).

\section{Ultrasonographic examination}

All retained urine calves were examined for the urinary bladder condition using $5 \mathrm{MHz}$ transabdominal transducer (Sonoscape A5V, China) in standing position just cranial to pelvic rim. Furthermore, a $6 \mathrm{MHz}$ transrectal transducer was used to examine the pelvic urethra.

\section{Surgical management}

All retained urine calves were subjected to tube cystostomy technique as described previously $[3,4,11-13,26]$. Before surgery, the calves were secured in dorsal recumbency. The area from the pubic bone until umbilicus was aseptically prepared. Linear infiltration anesthesia was performed using lidocaine HCL 2\% (Debocaine ${ }^{\circledR}$, the Arab Company, Obour City, Egypt) at the left paramedian region extended $10 \mathrm{~cm}$ cranially from the rudimentary teat. Calves with bladder rupture were sedated using $0.2 \mathrm{mg} / \mathrm{kg}$ of Xylazine HCL 2\% (Xyla-Ject ${ }^{\circledR}$, ADWIA Pharmaceuticals Co., $10^{\text {th }}$ of Ramadan City, Egypt). A $10 \mathrm{~cm}$ skin and S/C incision were performed at the anesthetic site parallel to preputial sheath, then the muscle and peritoneum were incised. Through a new $1 \mathrm{~cm}$ abdominal wall incision cranial to the first one, 18 French Foley catheter was implanted in the abdomen, then inside the bladder lumen through a stab incision in its wall (Figure-1). The catheter was fixed in the bladder and abdominal wall by simple suture. In case of the bladder rupture, cystorrhaphy was performed with Cushing suture pattern using Vicryl No. 1 sutures followed by Foley catheter placement after necessary debridement of necrotic parts and removal of concretion and cystic calculi through irrigation with normal saline solution. Peritoneal lavage was performed using sterile $0.9 \%$ saline solution. The abdominal incision was then routinely closed, and the skin was closed with horizontal mattress sutures using silk No. 2.

Parenteral administration of antibiotic (Pen\&Strep ${ }^{\circledR}$, Norbrook Co., N. Ireland, $1 \mathrm{~mL} / 25 \mathrm{~kg}$ ) for successive 5 days and anti-inflammatory (flunixin meglumine, Flunixin ${ }^{\circledR}$, Norbrook Co., N. Ireland, $2.2 \mathrm{mg} / \mathrm{kg}$ ) for successive 3 days was performed. The operated calves were orally administered $10 \mathrm{~g}$ of ammonium chloride dissolved in $40 \mathrm{~mL}$ of water for 20 days postoperatively. Intermittent blockade of the Foley catheter for 30 min 3 times daily until normal urination has occurred. Skin stitches were removed within 12 days after surgery.

\section{Statistical analysis}

The obtained data were analyzed using R3.1.3 software (R Foundation for Statistical Computing,

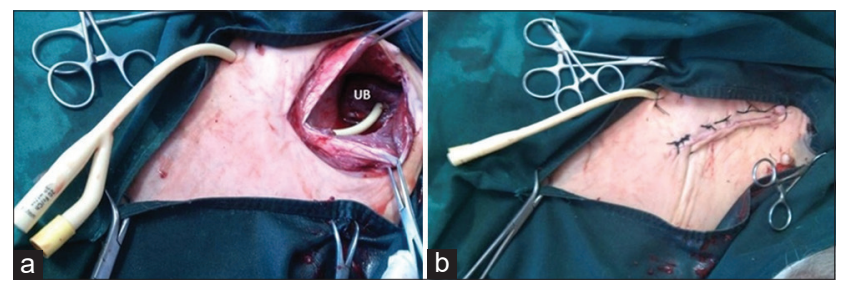

Figure-1: Tube cystostomy technique. (a) Foley catheter implantation inside the bladder through an abdominal incision. (b) Fixation of the Foley catheter outside the body and suturing the abdominal incision. UB=Urinary bladder. 
Vienna, Austria). The Mann-Whitney U-test was used to investigate the statistical difference between serum levels of Vitamins A and $\mathrm{D}, \mathrm{Ca}, \mathrm{Ph}$, urea, and creatinine in control and diseased calves as their values were not normally distributed. Statistical significance was set at $p<0.05$. The percentage of urine retention cases per month during the study period (2018-2020) calculated using the following formula: Retained urine cases $\%$ per month $=\mathrm{n}$ (sum of retained urine cases per month)/total number of cases during the study period. The Kruskal-Wallis test was used to assess the seasonal variation of cases.

\section{Results}

Based on clinical and ultrasonographic findings, the calves were diagnosed as obstructive urolithiasis with intact bladder ( $\mathrm{n}=64$ calves) or with bladder rupture ( $\mathrm{n}=85$ calves).

\section{Clinical findings}

The clinical findings of calves with retained urine are summarized in Table-1. Calves with intact bladder showed signs of anuria, anorexia, abdominal pain, urethral pulsation, and raised tail with protrusion of anal mucous membrane. On the other hand, calves with bladder rupture showed signs of anuria, pear-shaped abdomen with fluid thrilling in $85.9 \%$ of calves, decreased food intake, sunken eye in $87.1 \%$ of calves, dehydration, uremic breath in $62.3 \%$ of calves, and roughened coat with bran-like scales. Recumbency was reported in $16.5 \%$ of calves with bladder rupture. The duration of retention ranged from 1 to 3 days in calves with intact bladder and from 4 to 7 days in calves with bladder rupture. Abdominocentesis revealed presence of free urine inside the abdomen in calves with bladder rupture.

The percentages of retained urine in buffalo calves within different seasons during the study period are summarized in Table-2. Non-significant differences between the percentages of cases based on seasons $(p=0.44)$ were observed with peak incidence during the winter months with respective percentages of $17.5 \%, 21.5 \%$, and $19 \%$ for December, January, and February.

\section{Biochemical findings}

The biochemical findings of the retained urine calves and normal calves are illustrated in Table-3. The serum levels of the Vitamins A and D in retained urine calves were significantly lower than those of the control ones $(p=0.01$ and 0.002 , respectively). Furthermore, the serum levels of calcium in retained urine calves were significantly lower than the control calves ( $p=0.03$ ), while the serum levels of urea and creatinine in calves suffered urine retention were significantly higher than the control ones $(\mathrm{p}=0.01$ and 0.02 , respectively).

\section{Ultrasonographic findings}

The ultrasonographic imaging of calves with intact bladder showed distended anechoic bladder sac with circumscribed hyperechogenic contour inside the abdomen in transabdominal examination and distended pelvic urethra to be more than $1 \mathrm{~cm}$ when examined transrectally (Figure-2). While, the sonographic picture of calves with ruptured bladder showed free anechoic fluid inside the abdomen and the bladder appeared smaller in size (Figure-3).

\section{Surgical outcomes}

During the surgical procedure, the urinary bladder was found intact in 64 calves and ruptured in 85 calves. The site of bladder rupture was varied from dorsum to ventral aspect and vertex to neck of the bladder. The dorsal neck rupture was reported in 61 cases while dorsal vertex was reported in 11 cases. The ventral vertex was reported in five cases, while subserous rupture was reported in nine cases. The bladder appearance was smooth, and its color varied from pinkish to dark

Table-1: Clinical findings in buffalo calves with obstructive urolithiasis.

\begin{tabular}{|c|c|c|c|c|}
\hline \multirow[t]{3}{*}{ Parameters } & \multicolumn{4}{|c|}{ Calves with obstructive urolithiasis $(n=149)$} \\
\hline & \multicolumn{2}{|c|}{ Intact bladder $(n=64)$} & \multicolumn{2}{|c|}{ Bladder rupture $(n=85)$} \\
\hline & $\mathbf{n}$ & $\%$ & $\mathbf{n}$ & $\%$ \\
\hline Restlessness & 64 & 100 & 8 & 9.4 \\
\hline Dullness and depression & 0 & 0 & 76 & 89.4 \\
\hline Anorexia & 47 & 73.4 & 65 & 76.5 \\
\hline Sunken eyes & 19 & 29.7 & 74 & 87.1 \\
\hline Congested conjunctival mucosa & 37 & 57.8 & 66 & 77.6 \\
\hline Alteration in vital signs & 29 & 49.1 & 62 & 72.9 \\
\hline Reduced or absent Rumen motility & 37 & 57.8 & 65 & 76.5 \\
\hline Abdominal pain syndrome & 57 & 89.1 & 0 & 0 \\
\hline Pear-shaped distended abdomen & 0 & 0 & 73 & 85.9 \\
\hline Detectable fluid thrill abdomen & 0 & 0 & 80 & 94.1 \\
\hline Difficulty in movement & 0 & 0 & 22 & 25.9 \\
\hline Roughness of the coat & 34 & 53.1 & 73 & 85.9 \\
\hline Bran-like scale on the skin & 30 & 46.9 & 50 & 58.8 \\
\hline Uremic breath & 0 & 0 & 53 & 62.3 \\
\hline Urethral pulsation & 51 & 79.7 & 0 & 0 \\
\hline Rectal prolapse & 3 & 4.7 & 2 & 2.3 \\
\hline Recumbency & 0 & 0 & 14 & 16.5 \\
\hline
\end{tabular}


blue in 64 calves with intact bladder. In 61 calves with bladder rupture, the urinary bladder was rough, corrugated, and necrosed. Furthermore, the bladder was adhered to the peritoneum, omentum, mesentery, or intestine in 15 calves with bladder rupture.

All operated calves were followed up until normal urination has occurred. About $95.3 \%$ of calves $(\mathrm{n}=145)$ returned normal urination within 7-14 days after surgery, while $2 \%$ of calves returned normal urination after 30 days from surgery. Only $2.7 \%$ of the operated calves showed complications of Foley catheter loosening and obstruction. The Foley catheter was removed after resuming normal urination from the external urethral orifice and the owners were advised to supply more water and less concentrated feeding. About 128 calves were followed for 5 months after surgery without recurrence.

\section{Discussion}

Urolithiasis is a life-threatening disease of ruminants and of high economic importance to the farmers due to a high mortality rate resulted from the ruptured urinary bladder and the treatment costs [4]. Recent Egyptian studies were conducted regarding this condition $[7,13]$, the former study reported the comparative diagnosis of retained urine cases, while the latter one discussed the clinical findings, serum analysis, and the surgical management of obstructive urolithiasis in male buffalo calves. These studies lack the evaluation of serum levels of Vitamins A and D.

The age of all admitted calves was ranged from 3 to 7 months. This age was susceptible for obstructive urolithiasis in buffalo calves as reported in the

Table-2: Monthly distribution of retained urine cases.

\begin{tabular}{lcc}
\hline Months & Cases & Percentage \\
\hline January & 32 & 21.5 \\
February & 28 & 19 \\
March & 16 & 10.5 \\
April & 8 & 5.5 \\
May & 1 & 0.5 \\
June & 1 & 0.5 \\
July & 1 & 0.5 \\
August & 1 & 0.5 \\
September & 2 & 1.5 \\
October & 11 & 7.5 \\
November & 22 & 15 \\
December & 26 & 17.5 \\
\hline
\end{tabular}

previous studies $[4,7,13]$. Such findings might be attributed to the weaning of male buffalo calves that accompanied by diet shifting to high concentrates, and this could be favored by limited water intake in cold months as presented in the present study [27].

Nearly $58 \%$ of retained urine cases were recorded in winter months (December, January, and February) throughout the study period, although the seasonal variation was non-significant. These findings were consistent with the previous studies $[2,6,27,28]$. On the other hand, a previous study reported a higher incidence of urolithiasis in summer [29]. Decreased water intake with high concentrate feeding and low carotene-containing berseem that usually fed in winter could account for higher cases of incidence during winter months [27].

The most reported signs related to urolithiasis with intact bladder were anuria, restlessness, anorexia, abdominal colic pain, urethral pulsation, and raised tail. These signs agreed with previously described [30]. Contrastingly, calves with bladder rupture showed signs of anuria, anorexia, dullness, dehydration, sunken eye, abdominal distension with thrilling, rough coat, and uremic breath, these findings were reported in calves with bladder rupture in the previous studies [7,11].

Alterations in the vital signs were reported in all calves suffered urolithiasis with intact or ruptured bladder. The changes in vital signs and general condition of the diseased calves were correlated to the duration of retention and the condition of the urinary bladder. In general, the calves with short duration of retention and kept bladder intact were in superior condition than calves with long duration of retention and bladder rupture with accumulation of urine in the peritoneal cavity (uroperitoneum). This might be related to the metabolic changes associated with uroperitoneum [29].

In the present study, the duration of retention may give a tentative diagnosis of the case, anuria for 1-3 days indicating intact bladder while anuria for more than 3 days indicating complications with bladder rupture. Similar observations were reported previously $[7,29]$. The long duration of the illness might be attributed to lack of attention by the owners or delay of admission due to misdiagnosis of the cases and failed treatment trials [7]. Ultrasonography is a

Table-3: Serum parameters in healthy and retained urine calves reported as mean \pm SD and ranges.

\begin{tabular}{|c|c|c|c|c|c|c|}
\hline \multirow[t]{2}{*}{ Serum parameters } & \multicolumn{3}{|c|}{ Healthy group } & \multicolumn{3}{|c|}{ Urine retention group } \\
\hline & Mean \pm SD & Min & Max & Mean \pm SD & Min & Max \\
\hline Vitamin $A(\mu \mathrm{g} / \mathrm{dL})$ & $43.2 \pm 10.3$ & 31.9 & 52.2 & $7.3 \pm 4.4$ & 2.4 & 13.7 \\
\hline Vitamin $\mathrm{D}(\mathrm{ng} / \mathrm{mL})$ & $39.4 \pm 12.9$ & 24.9 & 49.8 & $8.3 \pm 4.9$ & 1.1 & 14.8 \\
\hline Urea $(\mathrm{mg} / \mathrm{dL})$ & $43.8 \pm 13.5$ & 31.3 & 58.2 & $295 \pm 80$ & 227.1 & 432.4 \\
\hline Creatinine $(\mathrm{mg} / \mathrm{dL})$ & $1.1 \pm 0.3$ & 0.8 & 1.5 & $8.65 \pm 7.8$ & 0.9 & 25.1 \\
\hline Calcium (mg/dL) & $9.8 \pm 1$ & 8.7 & 10.6 & $6.4 \pm 2.5$ & 1.4 & 9.8 \\
\hline Phosphorus (mg/dL) & $7.2 \pm 0.3$ & 6.8 & 7.5 & $8.7 \pm 0.9$ & 6.7 & 9.7 \\
\hline
\end{tabular}

$\mathrm{SD}=$ Standard deviation

Veterinary World, EISSN: 2231-0916 

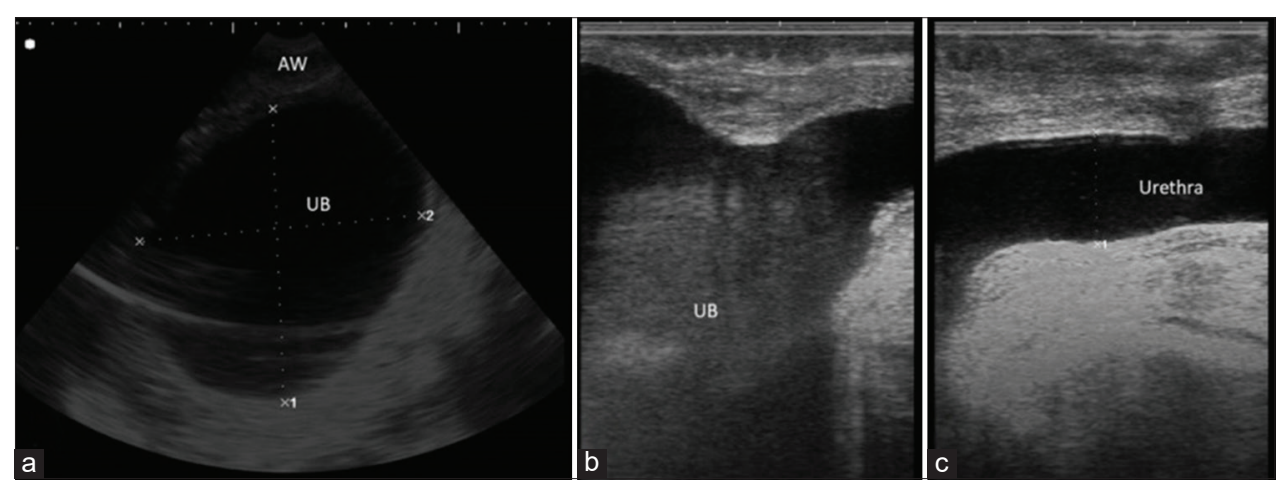

Figure-2: Ultrasonographic scanning of bladder and urethra. (a) Transabdominal ultrasonographic image of distended bladder in a male buffalo calf at the ventral abdomen in front of the scrotum after 2 days from retention. The bladder appeared as a distended anechoic sac with a hyperechoic wall. ( $b$ and $c$ ) Transrectal ultrasonographic image of the distended bladder and urethra, respectively, in the male buffalo calf. Note the distended pelvic urethra. UB=Urinary

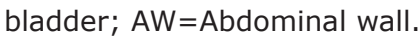
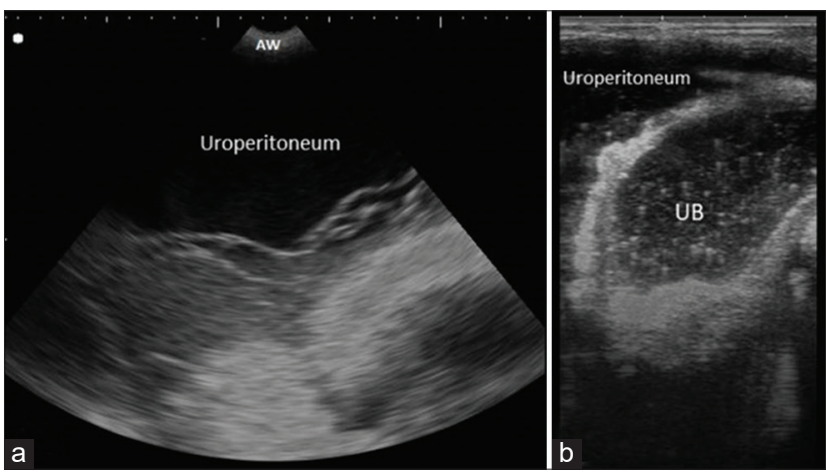

Figure-3: Ultrasonographic scanning of bladder. (a) Transabdominal ultrasonographic image of the bladder rupture in a male buffalo calf at the ventral abdomen in front of the scrotum after 5 days from retention. Note free anechoic fluid inside the abdomen. (b) Transrectal ultrasonographic image of the bladder rupture in the male buffalo calf. The bladder appeared smaller than normal with a thickened hyperechoic wall with anechoic fluid infiltration in the abdomen (uroperitoneum). UB=Urinary bladder; $\mathrm{AW}=$ Abdominal wall.

good diagnostic tool for different internal disorders, especially in cattle and buffaloes [31,32]. It is helpful in determining the conditions of the urinary system, especially the kidneys and urinary bladder [7,33,34]. It is considered the primary diagnostic imaging technique in diagnosis of cases with obstructive urolithiasis [35]. In the present study, ultrasonography was very helpful and diagnostic in cases with bladder atony. It helps to visualize the bladder contour and uroperitoneum in bladder rupture cases [7,34].

In normal healthy calves, the urinary bladder appeared round to oval anechoic sac inside the pelvis in transabdominal examination [36]. While in calves with intact bladder, the urinary bladder appeared severely distended sac with distal acoustic enhancement inside the abdomen in transabdominal examination. In transrectal examination, the pelvic urethra appeared distended with increased diameter of more than $1 \mathrm{~cm}$. On the other hand, the transabdominal examination of calves with bladder ruptures revealed small-sized bladder sac with thickened hyperechogenic wall and floating omentum and viscera in free anechoic fluid inside the abdomen. Similar imaging features were observed in the previous studies [37].

The serum levels of urea and creatinine in the retained urine calves were significantly higher than the control ones. These changes might be due to reduce the rate of glomerular filtration due to the back pressure on the kidneys in intact bladder cases and increase absorption of urea and creatinine from the peritoneal cavity in bladder rupture cases [38]. It was reported that the measurement of serum urea and creatinine is considered the first step in diagnosing the defects in metabolic wastes excretion from the body [7]. The serum levels of phosphorus were higher in the retained urine calves than the healthy ones. Furthermore, secondary hypocalcemia to higher phosphorus level was reported in retained urine calves due to higher excretion of calcium in the urine. Same findings were reported in a previous study [7].

Vitamin A is very important vitamin and is required for healthy epithelization of the tissues. In addition, it has an important role in balance of the Vitamin D concentration [2]. Therefore, desquamation of urinary epithelium and insoluble urinary minerals and salts may be a suitable nidus for the formation of urinary calculi [18]. In the present study, hypovitaminosis A was significantly in the retained urine calves in comparison to the control ones. From this point, lowering the serum levels of Vitamin A may be considered a potential factor for occurrence of urolithiasis.

In this study, a significant hypovitaminosis D was found in retained urine cases compared to the control ones. Our findings agreed with some human medical studies [21-24] that found lowered Vitamin $\mathrm{D}$ levels in stone former patients. Vitamin D deficiency induces oxidative stress and kidney inflammation that might be a possible risk factor for stone formation [39]. On the other hand, hypervitaminosis $\mathrm{D}$ was reported to be associated with kidney stones formation that might be attributed to increase urinary calcium levels $[18,19,40]$.

Intraoperatively, the urinary bladder was found intact in 64 calves and ruptured in 85 calves. The site 
of bladder rupture was varied from complete dorsal neck ( $n=61$ calves) to dorsal vertex $(n=11$ calves) and ventral vertex ( $\mathrm{n}=5$ calves). The incomplete subserous rupture was reported in nine calves. The reason of bladder rupture may be due to weakness of the bladder muscles and transitional epithelium in the dorsum. The previous studies observed the rupture most commonly at the dorsum [41]. The subserous rupture may be due to the separation of the muscles rather than tearing. Smooth bladder surface with pinkish to dark blue color in 64 calves having intact bladder might be due to bladder over-stretching resulting venous congestion. Rough, corrugated, and necrosed bladder surface reported in 61 calves having bladder rupture might be due to contraction of the bladder after rupture. Adhesion of the bladder to the peritoneum, omentum, mesentery, or intestine in 15 calves might be due to their attachment with rough surface of the bladder after rupture.

The treatment of obstructive urolithiasis in ruminants is primarily surgical [42]. Tube cystostomy technique was found to be successful, rapid, simple, and easily applied procedure for treatment $[3,4,11-13,26,43,44]$. It has advantages over other surgical techniques of preservation breeding function of the animal and urinary continence [14]. All calves with intact bladder were treated surgically with tube cystostomy while calves with bladder rupture were treated with cystorrhaphy followed by tube cystostomy. Interestingly, most of the treated calves with tube cystostomy (95.3\%) had their normal flow of urination within 7-14 days postoperatively. These findings were in accordance with the previous studies $[3,13,26,14]$. This early response might be attributed to many factors; (1) reduction in urethral inflammation and spasm through administration of anti-inflammatory, (2) drying of the calculi after bladder evacuation using Foley catheter, (3) dissolving of urine using acidic agent such as ammonium chloride orally, and (4) in addition to bladder flushing using sterile saline solution $[44,45]$. Daily oral administration of $10 \mathrm{~g}$ ammonium chloride as urinary acidifier along with tube cystostomy has a synergistic effect for quick recovery of animals as suggested previously $[3,41,43]$.

In the present study, recurrence of the condition was not noticed in successfully treated calves during post-operative follow-up period of 5 months. It has been considered that the success of the surgical procedure when recurrence of the obstruction did not recur [46].

The surgical procedure was performed under local infiltration anesthesia at the site of surgery with satisfactory results. A similar anesthetic protocol was performed previously for surgical treatment of obstructive urolithiasis in ruminants using tube cystostomy technique $[3,47,48]$.

The complication of tube cystotomy in the present study was reported in $2.7 \%$ of the cases due to catheter loosening may be due to deflation of catheter bulb and catheter obstruction with blood or tissue debris. Prevention of recurrent obstructive urolithiasis was addressed by the use of urinary acidifiers and dietary management.

\section{Conclusion}

Obstructive urolithiasis was found to be highly incident in male buffalo calves. Young ages between 3 and 7 months, winter season, and hypovitaminoses $\mathrm{A}$ and $\mathrm{D}$ could be potential risk factors for occurrence. Tube cystostomy using Foley catheter was a practicable, quick, and reliable method for the management of such condition. Future large cohort studies are recommended to confirm the role of hypovitaminoses A and $\mathrm{D}$ in urolithiasis. The owners should be impressed with the importance of water consumption for animals with the risk of urolithiasis. This could be achieved by addition of salts to the ration to promote intake of large amounts of water and formation of large volume of diluted urine. Supplementation of vitamins to the ration on months of high incidence is very important in the prevention of urolith formation.

\section{Authors' Contributions}

All authors designed, planned, drafted, and revised the manuscript. AA contributed to statistical analysis. SE, EE, and MA contributed to clinical and ultrasonographic examinations in addition to surgical interference and post-operative follow-up of cases. YB contributed to clinical and ultrasonographic examinations. All authors read and approved the final manuscript.

\section{Acknowledgments}

The authors would like to thank Surgery and Animal Medicine Department, Faculty of Veterinary Medicine, Zagazig University, Egypt, for providing necessary facilitiesfor the present study. The authors did not receive any specific funds for this study.

\section{Competing Interests}

The authors declare that they have no competing interests.

\section{Publisher's Note}

Veterinary World remains neutral with regard to jurisdictional claims in published institutional affiliation.

\section{References}

1. Singh, S., Gera, K. and Nigam, J. (1981) Hematological and biochemical studying obstructive urolithiasis in bovine. Indian J. Vet. Surg., 2: 72-79.

2. Gugjoo, M., Zama, M., Amarpal, A., Mohsina, A., Saxena, A. and Sarode, I.P. (2013) Obstructive urolithiasis in buffalo calves and goats: Incidence and management. $J . A d v$. Vet. Res., 3(1): 109-113.

3. Tamilmahan, P., Mohsina, A., Karthik, K., Gopi, M., Gugjoo, M. and Zama, M.M. (2014) Tube cystostomy for management of obstructive urolithiasis in ruminants. Vet. World, 7(4): 234-239.

4. Sutradhar, B.C., Dey, T., Yadav, S.K. and Bostami, M.B. (2018) Surgical management of obstructive urolithiasis 
in small ruminants by tube cystostomy in Chittagong, Bangladesh. J. Agric. Sci. Technol. A, 8(1): 89-98.

5. Thakur, N., Choudhary, S.S., Chethan, G.E. and Dey, S. (2019) Urokinase alteration and its correlation with disease severity and oxidative/nitrosative stress in buffalo calves with obstructive urolithiasis. Res. Vet. Sci., 127: 18-26.

6. Rafee, M.A., Baghel, M., Palakkara, S. and Haridas, S. (2015) Obstructive urolithiasis in buffalo calves: A study on pattern of occurrence, aetiology, age, clinical symptoms and condition of bladder and urethra. Buffalo Bull., 34(3): 261-265.

7. Bayoumi, Y.H. and Attia, N.E. (2017) Comparative study of obstructive urolithiasis and its sequelae in buffalo calves. Vet. World, 10(2): 156-162.

8. Larson, B. (1996) Identifying, treating, and preventing bovine urolithiasis. Vet. Med., 91(4): 366.

9. Stone, W., Bjorling, D., Trostle, S., Hanson, P. and Markel, M. (1997) Prepubic urethrostomy for relief of urethral obstruction in a sheep and a goat. J. Am. Vet. Med. Assoc., 210(7): 939-941.

10. Williams, J. and White, R. (1991) Tube cystostomy in the dog and cat. J. Small Anim. Pract., 32(2): 598-602.

11. Khurma, J., Choudhary, C., Sharma, D.V. and Singh, K. (2017) Tube cystostomy for management of obstructive urolithiasis in buffalo calves. Int. J. Sci. Environ. Technol., 6(1): 413-419.

12. Mangotra, V., Singh, K. and Proch, A. (2017) Tube cystostomy in male buffalo calves (Bubalus bubalis) suffering from retention of urine. J. Anim. Res., 7(2): 279-291.

13. Abdalla, A. and Rizk, A. (2018) Clinical, haematological and biochemical findings based surgical management of obstructive urolithiasis by tube cystostomy in buffalo calves (Bubalus bubalis). Alexandria J. Vet. Sci., 56(2): 69-77.

14. May, K., Moll, H., Wallace, L., Pleasant, R. and Howard, R. (1998) Urinary bladder marsupialization for treatment of obstructive urolithiasis in male goats. Vet. Surg., 27(6): 583-588.

15. Misk, N. and Semieka, M. (2003) Clinical studies on obstructive urolithiasis in male cattle and buffaloes. Assiut. Vet. Med. J., 49(97): 258-274.

16. Andrews, A.H., Blowey, R.W., Boyd, H. and Eddy, R.G. (2008) Bovine Medicine: Diseases and Husbandry of Cattle. John Wiley and Sons, Hoboken, New Jersey.

17. Grases, F., Garcia-Gonzalez, R., Genestar, C., Torres, J. and March, J. (1998) Vitamin A and urolithiasis. Clin. Chim. Acta, 269(2): 147-157.

18. Radostits, O.M., Gay, C., Hinchcliff, K.W. and Constable, P.D. (2007) A textbook of the diseases of cattle, horses, sheep, pigs and goats. Vet. Med., 10: 2045-2050.

19. Drolet, R. (2019) Urinary system. In: Zimmerman, J.J., Karriker, L.A., Ramirez, A., Schwartz, K.J., Stevenson, G.W. and Zhang, J., editors. Diseases of Swine. John Wiley and Sons, Inc., Hoboken. p408-424.

20. Hu, H., Zhang, J., Lu, Y., Zhang, Z., Qin, B., Gao, H., Wang, Y., Zhu, J., Wang, Q., Zhu, Y., Xun, Y. and Wang, S. (2007) Association between circulating vitamin D level and urolithiasis: a systematic review and meta-analysis. Nutrients, 9(3): 301.

21. Elkoushy, M.A., Sabbagh, R., Unikowsky, B. and Andonian, S. (2012) Prevalence and metabolic abnormalities of Vitamin D inadequate patients presenting with urolithiasis to a tertiary stone clinic. Urology, 79(4): 781-785.

22. Pipili, C. and Oreopoulos, D.G. (2012) Vitamin D status in patients with recurrent kidney stones. Nephron Clin. Pract., 122(3-4): 134-138.

23. Girón-Prieto, M.S., del Carmen Cano-García, M., Arrabal-Polo, M.Á., Poyatos-Andujar, A. and QuesadaCharneco, M. (2016) Analysis of Vitamin D deficiency in calcium stone-forming patients. Int. Urol. Nephrol., 48(8): 1243-1246.

24. Ticinesi, A., Nouvenne, A., Ferraro, P.M., Folesani, G. and
Lauretani, F. (2016) Idiopathic calcium nephrolithiasis and hypovitaminosis D: A case-control study. Urology, 87: 40-45.

25. Jackson, P.G.G. and Cockcroft, P.D. (2002) Clinical Examination of Farm Animals. Blackwell Science Ltd., Hoboken. p113-124.

26. Parrah, J.U.D., Moulvi, B.A., Hussain, S.S. and Bilal, S. (2011) Innovative tube cystostomy for the management of bovine clinical cases of obstructive urolithiasis. Vet. Arhiv, 81(3): 321-337.

27. Amarpal, K.P., Aithal, H.P., Pawde, A., Pratap, K. and Gugjoo, M. (2013) A retrospective study on the prevalence of obstructive urolithiasis in domestic animals during a period of 10 years. Adv. Anim. Vet. Sci., 1(3): 88-92.

28. Mahajan, A., Gupta, A.K., Bhadwal, M.S., Bhat, M.A. and Bhardwaj, H.R. (2017) Occurrence and management of obstructive urolithiasis in ruminants. J. Anim. Res., 7(4): 723-731.

29. Singh, A., Gangwar, A. and Devil, K. (2014) Incidence and management of obstructive urolithiasis in buffalo calves and goats. Adv. Anim. Vet. Sci., 2(9): 503-507.

30. Kinjavdekar, P.A., Aithal, H.P., Pawde, A.M. and Pratap, K. (2010) Management of obstructive urolithiasis with tube cystostomy in a bullock. Indian Vet. J., 87(1): 65-67.

31. Abdelaal, A.M., Abd El Raouf, M., Aref, M.A. and Moselhy, A.A. (2019) Clinical and ultrasonographic investigations of 30 water buffaloes (Bubalus bubalis) with hepatomegaly. Vet. World, 12(6): 789-795.

32. Abd El Raouf, M., Elgioushy, M. and Ezzeldein, S.A. (2020) Congestive heart failure in cattle; etiology, clinical, and ultrasonographic findings in 67 cases. Vet. World, 13(6): 1145-1152.

33. Braun, U. (1993) Ultrasonographic examination of the left kidney, the urinary bladder and the urethra in cows. J. Vet. Med. A, 40(1): 1-9.

34. Sutaria, P.T., Patel, J.B., Patel, A.M., Patel, P.B. and Suthar, B.N. (2018) Modified tube cystotomy for management of obstructive urolithiasis in young male bovines: A review of 9 cases. J. Dairy Vet. Anim. Res., 7(3): 120-123.

35. Makhdoomi, D. and Gazi, M.A. (2013) Obstructive urolithiasis in ruminants a review. Vet. World, 6(4): 233-238.

36. Floeck, M. (2009) Ultrasonography of bovine urinary tract disorders. Vet. Clin. North Am. Food Anim. Pract., 25(3): 651-667.

37. Abdelaal, A.M., Al-Abbadi, O.S. and Abu-Seida, A.M. (2016) Transcutaneous and transrectal ultrasonography in buffalo calves with urine retention. Asian J. Anim. Vet. Adv., 11(21): 79-88

38. Sharma, P.D., Singh, K., Singh, J. and Kumar, A. (2006) Bacteriological, biochemical and histopathological studies in uroperitoneum in buffalo calves (Bubalus bubalis). Indian J. Anim. Sci., 76(2): 124-126.

39. Kliewer, S.A., Umesono, K., Mangelsdorf, D.J. and Evans, R.M. (1992) Retinoid X receptor interacts with nuclear receptors in retinoic acid, thyroid hormone and Vitamin D3 signalling. Nature, 355(6359): 446-449.

40. Tavasoli, S. and Taheri, M. (2019) Vitamin D and calcium kidney stones: A review and a proposal. Int. Urol. Nephrol., 51(1): 101-111.

41. Kushwaha, R.B., Amarpal, Aithal, H.P., Kinjavdekar, P. and Pawde, A.M. (2014) Clinical appraisal of 48 cases of obstructive urolithiasis in buffalo calves treated with tube cystostomy and urethrotomy. Adv. Anim. Vet. Sci., 2(2): 106-110.

42. Van Metre, D.C., House, J.K. and Smith, B.P. (1996) Obstructive urolithiasis in ruminants: Medical treatment and urethral surgery. Compend. Contin. Educ. Pract. Vet., 18(3): 317-328.

43. Parrah, J., Moulvi, B., Gazi, M.A., Makhdoomi, D., Athar, H., Hamadani, H. and Khan, Q. (2014) Evaluation of different surgical techniques for the management of bovine obstructive urolithiasis. J. Vet. Sci. Technol., 5(5). 
44. Rakestraw, P.C., Fubini, S.L., Gilbert, R.O. and Ward, J.O. (1995) Tube cystostomy for treatment of obstructive urolithiasis in small ruminants. Vet. Surg., 24(6): 498-505.

45. Ewoldt, J.M., Anderson, D.E., Miesner, M.D. and Saville, W.J. (2006) Short-and long-term outcome and factors predicting survival after surgical tube cystostomy for treatment of obstructive urolithiasis in small ruminants. Vet. Surg., 35(5): 417-422.

46. Fortier, L.A., Gregg, A.J., Erb, H.N. and Fubini, S.L. (2004) Caprine obstructive urolithiasis: Requirement for $2^{\text {nd }}$ surgical intervention and mortality after percutaneous tube cystotomy, or urinary bladder marsupialization. Vet. Surg., 33(6): 661-667.

47. Fazili, M.R., Bhattacharyya, H.K., Buchoo, B.A., Malik, H.U. and Dar, S.H. (2012) Management of obstructive urolithiasis in dairy calves with intact bladder and urethra by Fazili's minimally invasive tube cystotomy technique. Vet. Sci. Dev., 2(1): e11.

48. Gasthuys, F., Steenhaut, M., De Moor, A. and Sercu, K. (1993) Surgical treatment of urethral obstruction due to urolithiasis in male cattle: A review of 85 cases. Vet. Rec., 133(21): 522-526.

$* * * * * * * *$ 